\title{
A Study on Service Quality and Customer Satisfaction in Nigerian Healthcare Sector
}

\author{
Rajasekhara Mouly Potluri*, Gift Angiating**
}

Received: November 08, 2018. Revised: November 25, 2018. Accepted: December 05, 2018.

\begin{abstract}
Purpose - The core objective of the research is to explore the quality of services provided by the Nigerian health care sector that lead to know the satisfaction levels of the consumers.

Research design, data, and methodology - After a meticulous literature review, the researchers administered a two part questionnaire to know the service gaps and satisfaction levels of the customers. The research carried out with a sample of 400 respondents but received only 150 responses from the residents around Adamawa state. The collected data was edited, coded, and analyzed with the SPSS latest version with the descriptive and inferential statistical tools.

Results - Majority of the respondents expressed their discontentment over the responsiveness of the service providers when compared to tangibility and reliability quality variables. There is no relationship between the quality variable tangibility and overall satisfaction. Related to the overall satisfaction, 42 percent of respondents have neutral perspective indicated that they are either satisfied or dissatisfied as against the 43.3 percent of dissatisfied customers.

Conclusions - This research proffers invaluable information to the entire Nigerian health-care sector to review their existing delivery of services to improve patient satisfaction. This research is first of its kind concentrated to know the quality of health-care services and customers overall satisfaction in Nigeria.
\end{abstract}

Keywords: Service Quality, Customer Satisfaction, SERVQUAL, Health-Care, Nigeria.

JEL Classifications: I11, M31, M39, N77.

\section{Introduction}

With the recent increase in demand for patient satisfaction, it is unquestionable why there is also an increase in demand and search for quality healthcare services from our healthcare providers in our society, which is believed to be the one of the reasons behind patient satisfaction. Recent developments and competition in the hospitality sector, particularly the health care sector and hospitals, have seen the emergence of major competition between the private health care providers and the public health care providers. "The health sector in Nigeria is facing a major human resources crisis. It has been a challenge trying to understand why with the large human resource

* Corresponding Author, Dr. Associate Professor, Business Administration \& Marketing, School of Business \& Entrepreneurship, American University of Nigeria.Yola, Adamawa State, Nigeria. Tel: +234-805-980-4112, E-mail: raja.potluri@aun.edu.ng

** Graduating Student, School of Business \& Entrepreneurship, American University of Nigeria, Yola, Adamawa State, Nigeria. Tel: +234-803-645-7734, E-mail: gift.angiating@aun.edu.ng base the nation prides itself about, there still exists a huge deficiency in the health workforce"(Okafor, 2017). In the society we exist in, it is believed that quality and reliable health care services can only be gotten in the private health care providers, and this can be attributed to the fact that the private hospitals tend to be more equipped and maintained, in terms of resources. This is in addition to the fact that the doctors and nurses in the private sector tend to have a more personal relationship with their patients which makes them feel more appreciated and comfortable around private medical practitioners. There is trust developed between the patient and the doctor through a more professional and confidential approach. According to Arsanam(2014) it was implied that quality service is the actual quality of service that the customer initially expected prior receiving services. This means that certain customers may already have their expectations about a particular organization and their mode of services which they have believed would be satisfactory enough, prior receiving the expected service and this is what drives the satisfaction of that customer. In the business world however, quality service 
is one of the primary factors that illustrates the principles of a successful business organization, in the health care sector also it could be seen as a driving factor as to why patients return to a particular hospital frequently for more services after every experience. In healthcare facilities, quality service is very important seeing as it is a very sensitive environment, and the nature of the people commonly found within hospital premises require sensitivity, and satisfactory health care services. Just like other parts of the world, in Nigeria also significant variances can be observed in terms of delivery of services irrespective of the sector. There is no exception to the health-care also. It is believed that the quality of service provided by public health care providers is usually low and shambolic; this is in terms of structure, organization and allocation of responsibilities. Employees in this sector are usually perceived as nonchalant, and mostly unprofessional about how they render services to patients, and in most cases tend to carry out their frustration on patients which they are expected to care for. As health care providers, they are expected to nurse and be more committed to improving the health of patients, through provision of quality medical services. The patients on the other hand tend to have no other option but to accept the quality of service they are being offered, seeing as they either may be facing financial constraints and cannot afford the private health care treatment, or the patients have little or no knowledge on what quality service is and tend to settle for what is generally tolerated and accepted. Different researches have however provided information backing the ideology that certain patients may lack the basic knowledge on how to judge service quality, thus relying on their perceptions and expectations as a medium for assessing service quality. Nevertheless, "service quality is customer's perceptions and it is judged by them in person not by organizations"(Zeithaml There is no reference, 1990). According to Zeithml(1988), "Service quality has been defi ned as a consumer's evaluative judgment regarding the degree of superiority of service performance". In judging quality service in health care centers, the criteria being analyzed would range from environmental and surrounding factors to the manner of approach towards patients and responses to their problems including professionalism of the hospital staff. Its' primary purpose is to satisfy the patient or client being attended to, and ensuring that their demands are met satisfactorily as this further projects a good reputation about the hospitals. The researchers has initiated this study with the core objective of identifying the quality of services offered by the Nigerian health-care providers along with the overall satisfaction levels of the customers.

\section{Literature review}

Overtime, there has been a continuous demand for quality health care service, most especially in the public hospitals and health care facilities. Studies initiated by various researchers have continued to generate different perspectives and ideologies as to what factors drive patient satisfaction, and how quality service can be measured. Two prominent academicians Gronroos(1984) and Lam(1997) defined the term "service quality to be measured as technical and functional quality, where technical quality in the health care sector is defined primarily on the basis of the technical accuracy of the medical diagnoses and procedures, or the conformance to professional specifications, while functional quality refers to the manner in which the health care service is delivered to patients." Implying that, quality service could be defined based on the process and method in which the service is being delivered to the customer. In relation to the health care sector, this implies that quality health care service in hospitals is expected to comprise of the relationship between the hospital staff and the patients, the communication level, as well as the amount of attention and level of professionalism being shown to the patients by the hospital staff. Quality service maximizes the possibility of the customers returning to their health care providers for more services, and is a key factor in terms of profit generation for organizations, as well as an influential factor that provides competitive advantage(Brown \& Swartz, 1989). Existing customers could inform other potential customers through word of mouth about their experiences with the quality of services being offered in the hospital, which is an effective means of product promotion, and could generate their interest thus improving the profitability of the health care provider. In some other cases however, certain customers tend to base their evaluation of quality service on environmental factors within and around the hospital premises. "Due to the intangibility nature of the services, consumers will look for tangible physical evidence such as equipment, appearance of employees, environmental design, décor signage, to form their expectations(Sureshchander There is no reference, 2002)." Available information from studies carried out by previous researchers has shown that professionals however deemed this outcome insignificant(Yeșilada, 2010).

An article on quality service, quoted that "Service quality is measured as a technical and functional quality,"(Gronroos, 1984). Implying that it's a cumulative of both the manner in which the service is delivered, as well as, the process of delivering the service. Never the less, most of these theories are aimed at pin pointing those factors that guarantee either customer satisfaction or their return, while identifying those factors that helps an organization achieve this motive. Service quality in healthcare sector as defined by the researchers like Kalaja, Myshketa, and Scalera(2016) is "the difference between customer expectation and perception as it is being received by the customer, because consumer's perception is the main indicator of quality in health care service." Thus stating that, in the healthcare sector the patients' perception and satisfaction is very important 
because, satisfaction is the key measurement of quality service, and also a satisfied patient will have more positive reports on the quality of service and this information is usually more influential when convincing potential patients about the quality of services offered by a particular hospital. In addition to that, patient perception helps to indicate insight to the mental rating an individual has about an organization, and their views could also provide an insight as to how the services can further be improved upon. With this study, in addition to identifying the quality of services that are being provided to patients at healthcare centers located in Yola and Abuja, the researchers also aimed at identifying those factors which stimulate the satisfaction of the existing patients and their attendants, while trying to identify a means in which the quality of service at health centers can be made better to provide sustainable competitive advantage. Earlier studies have indicated that patient satisfaction in hospitals is perceived as an emotional response to evaluation of services offered(Westbrook, 1981), implying that patients level of satisfaction is based on their feelings rather than the quality of services being offered. In a country like Nigeria, quality medical services are only available in the private healthcare centers due to comprehensive nature of dedicated delivery of the service. But the situation in public healthcare centers is completely different where the service quality and commitment is abysmal which influences the satisfaction levels of the public. The difference between the delivery of service quality in the two healthcare sectors proliferate the researchers to take-up the research in identifying exact contentment levels spread among the Nigerians.

\subsection{Conceptual framework}

Nigeria, the most populated country in Africa and the $7^{\text {th }}$ most populated country in the world, since her independence has undergone and is still undergoing various processes of progressions. Engulfed by both highlands and wildlife, Nigeria is one of the most vegetated lands, as well as, home to various natural mineral resources, ranging from crude oil to cocoa, copper, etc. The healthcare sector in this part of Africa is still going through a structural process whereby, there are still major discrepancies in the provision of healthcare services, when it comes to quality. "According to the 2009 communique of the Nigerian national health conference, healthcare system remains weak as evidenced by lack of coordination, fragmentation of services, dearth of resources, including drug and supplies, inadequate and decaying infrastructure, inequity in resource distribution, and access to care and very deplorable quality of care." (Welcome, 2011). Meaning the Nigerian healthcare sector is lacking in every aspect, thus, creating a need to restructure and address medical service quality that is being distributed nationally. Like every other part of the world, there are two sectors that cater to healthcare services, the private and the public health care sector. Each sector varies in cost and quality of services, and these differences are evident when it comes to preferences in terms of quality. In tackling the quality of services that is provided in our healthcare centers, a SERVQUAL statement questionnaire (Parasuraman, Zeithaml, \& Berry, 1988), would be used in the collection of primary data. This SERVQUAL statement was first designed by academic researchers, A. Parasuraman, Leonard Berry, and Valarie Zeithaml, with the aim of measuring quality of service in organizations. The original statement was designed using 5 dimensions, with 22 questions aiming at identifying the quality of service being provided by any organization in the service sector.

Tangibles (4): This criterion has four questions which focuses mainly on analyzing the physical environment of the organization and its appearance.

Responsiveness (4): This criterion also has four questions which focuses on the promptness with which organizational staff, respond to customers' needs and their willingness to help them through processes.

Reliability (5): This criterion on the other hand, contains five questions which seek to identify the ability of the staff to conduct services properly and dependably without close supervision.

Empathy (5): In this criterion, there are five questions focusing on the amount of personal attention being provided to the customers by the organizational staff.

Assurance (4): This criterion has four questions identifying how much knowledge of duty, workers at an organization possess, and the ability instills confidence customers.

According to past research information, patient satisfaction in hospitals is perceived as an emotional response to evaluation of services offered(Westbrook, 1981). In a hospital environment, there are a lot of surging emotions. It is expected that a certain level of sensitivity is displayed by those working in such environment. This is because of the sensitive nature of individuals found in health care facilities, and the care that is needed when responding to their needs. "Some services, such as health care services, which are high in credence qualities have a wide interpretative margin meaning that consumers have the tendency to assess the quality based on their perceptions and reality;" (Purcarea, Gheorghe, \& Petrescu, 2013). Thus, the nature of a service demand and the swiftness of response by the hospital staff, could influence a patient's perception after being served. In addition to that, a patient could misinterpret quality service as the ability of that hospital to solve that predicament, irrespective of the mode of service provision. However, certain theories imply that, patient satisfaction comes as an outcome of the service or treatment being received(Schoenfelder, Klewer, \& Kugler, 2011). Thus implying that, patient satisfaction globally, is facilitated by receiving treatment for a particular ailment. In addition to that, it was also stated that, "Possibly, patients look for 
surrogate indicators of correct diagnosis and treatment to measure their own satisfaction"(Schoenfelder et al., 2011). Meaning that, patients are prone to seeking alternative diagnosis which could suffice and also be described as quality service. However, other studies have also gone to indicate that patient satisfaction can also be attributed to evaluation of the structure and facilities available in these hospitals, "Results reported by Parasuraman and Zeithaml and Boshoff and Gray approved the results and stated that patients' perceptions of quality were mainly affected by environment and physical evidence than the core services" (Mohebifar, Hasani, Barikani, \& Rafiei, 2016).

Based on the above literature review and theoretical framework, the researchers have chosen the following list of hypotheses.

HO : Patient satisfaction is not based on the quality of service, but solving the problem at hand

$\mathrm{H1}$ : Patient satisfaction is based directly on the quality of services being offered by the organization.

$\mathrm{H} 2$ : The quality of service is directly proportional to the state of the infrastructure, and the appearance of the environment.

\section{Research Methodology}

This study was conducted through a quantitative method of research. Both primary and secondary sources of information were used in compilation of this report. All primary information that was collected in relation to this study was limited solely to participants who had already received medical services at the Federal Medical Center, Yola. They voluntarily obliged to participate in the study after reading, understanding, and agreeing to the terms on the adult consent form provided to them before commencement of study. Collection of primary data was conducted around the hospital premises and within Yola, Adamawa state. There was no need in acquiring permission from the hospital for collection of data, as out patients were the only selected participants for the study. A two-part questionnaire was designed for collection of primary data using the modified SERVQUAL statement, which is used in measuring service quality in business organizations. The first part of the questionnaire highlighted demographic profile of the respondents and the second part concentrated on measuring the service quality and customer satisfaction. The participants were required to fill out these questionnaires indicating certain levels of satisfaction on a particular service. Information in the questionnaire was simplified and modified to ensure that participants who understood the simple use of English could easily read, understand and respond to the questions being asked in the questionnaire without complications. The required secondary data for the completion of this research article collected from the journals, magazines, websites, sector specific articles in newspapers, e-books, etc. A sample size of 400 people who were above the ages of 18 was approached for the collection of data. The sample area was Yola/Jimeta, Adamawa state in Nigeria. Also as a post-service study, information was collected solely from customers who had already received services or treatment from different health-care providers in the said research areas. The sample population was limited to only customers or patients who understood the basic and fundamental application of English, thus eliminating the need for an interpreter. During selection, a stratified sampling method was applied, and participants were categorized under three different groups; gender, in-patients and out-patients. Participants were approached irrespective of gender or age differences, provided they were ages 18 and above. The collected data was edited, coded, and analyzed with the SPSS latest version with the descriptive(mean, median, frequencies) and inferential statistical tool Carl Pearson Co-efficient of Correlation.

\section{Analysis and Discussion}

The perusal of this part of the research focuses on the demographic profile of the respondents, analysis of all the service quality variables and overall satisfaction of the Nigerian customers towards health-care services along with testing of hypotheses. Out of a 150 respondents who volunteered to take part in this study, 105 of them were males, while the other 45 people were females. Although there was no particular age focused on, a higher percentage of the respondents, $58 \%$ of them, were within the $25-40$ range of age classification. In addition to that, most of the respondents had attained the undergraduate level of educational qualification as against $8.7 \%$ of below secondary grade and only $6 \%$ postgraduates. For effective and reliable feedback, information concerning this study was collected from candidates who had received treatment or services at different health-care services providers in Yola/Jimeta towns. This particular criterion was important so as to provide an insight as to the quality of services they received and their perceptions.

Table 1: Demographic Profile of the Respondents.

\begin{tabular}{|c|c|c|c|}
\hline Label & Description & Frequency & Population \\
\hline Age & $18-24$ & $38.0 \%$ & 57 \\
& $25-40$ & $58.0 \%$ & 87 \\
& $40-60$ & $3.3 \%$ & 5 \\
& $60-$ Above & $0.7 \%$ & 1 \\
\hline Gender & Male & $70 \%$ & 105 \\
& Female & $30 \%$ & 45 \\
\hline Education & Below secondary & $8.7 \%$ & 13 \\
& Undergraduate & $85.3 \%$ & 128 \\
& Postgraduate & $6.0 \%$ & 9 \\
\hline
\end{tabular}




\section{Analysis of the Service Quality Parameters}

Patient perception towards quality of service can be based on certain variables and in collecting information, the most widely used SERVQUAL statement(Parasuraman et al., 1988), was modified to ease the classification of the patients' perception. Evaluating their perception or expectation of services was analyzed using the correlation between the patients overall satisfaction of the service received and SERVQUAL variables. All the independent variables, Tangibles, Reliability, Responsiveness, Assurance and Empathy, were analyzed in SPSS 20 using correlation to check for the significance they had on each other, and the cumulative impact they have on patient satisfaction. For determining significance, $\mathrm{P}$ value $=0.00<0.05$ which is mentioned in Table 3.

Related to tangibility criterion in the questionnaire, researchers raised four questions which mainly focus on the physical appearance of the medical facility. Analyzing the information was necessary in providing the insight as to the impact or relationship the physical appearance of an organization could have on the overall customer satisfaction or the services provided by the healthcare center. In analyzing this criterion, correlation was used to check the significance and the relationship between the tangibles and all the other independent variables. Available statistics after data analysis indicate that there is a significant relationship between the reliability, responsiveness and the empathy, with significant values of $\mathrm{P}=0.00<0.05$, for Reliability, $\mathrm{P}=$ $0.45<0.05$ for Responsiveness and $P=0.00<0.05$, Table 3. This implies that there is a correlation between the behavioral conduct of staff of the hospital and the amount of attention provided to customers. However, the Tangibles has no significant relationship with the overall satisfaction of the customer as indicated in Table 3, there is no significant relationship or impact the physical appearance has on the overall satisfaction of services being offered to the respondents. The second criterion reliability focuses on how the 5tredsdsstaff was able to carry out services dependably, without being closely supervised while also indicating the amount of knowledge they have on their occupation, and their job description. This was important for this study because in analyzing quality of service, it is necessary to know the level of understanding the workers have of their job description and expectations, as these attributes transcend and can be reflected in the confidence in which they execute their services. Using correlation, the researchers were able to analyze the relationship between the reliability and other variables, and the possible impact or relationship on the overall satisfaction of the patients. According to analysis, there is no significant relationship between the reliability and other variables apart from the tangibles, $\mathrm{P}=0.00<0.05$, meaning that, there is a relationship between physical environment of the hospital and how much knowledge the staff have of their job description. Implying that, increasing the standard of the physical environment creates an avenue for increase in standard of employed staff. However, there is no impact this has on the overall satisfaction of the respondents, $\mathrm{P}=$ $0.276>0.05$, with the originally set significance value being $P=0.00<0.05$. Regarding responsiveness, this variable capitalizes on how swiftly staff of the healthcare center responded to the health disorders of the patients. It analyzes the time taken for the medical staff to respond to patients' needs, and their willingness to assist them through the process. In quality service, it is imperative that swift response to customers' demands is focused on. This is because patients are pleased when services are concise and on time, thus, while conducting this study the time taken for the healthcare workers to respond to the needs of customers was necessary in analyzing the quality of service being delivered by the hospital workers. The analysis shows that there is a significant relationship between the tangibles, assurance and empathy variables on the service quality statement, with significance values of $P=0.00<0.05$, Tangibles $\mathrm{P}$ Value $=0.45<0.05$, Assurance $\mathrm{P}$ value $=0.10$ $<0.05$ and Empathy $P$ Value $=0.00<0.05$. This implies that the time taken for staff to respond to customer needs is directly related to the amount of personal attention that will be shown to customers, and this also directly impacts the customers confidence in the services offered at the organization. However, based on overall satisfaction, there is no correlation between the responsiveness and the overall satisfaction of the patient with $P$ value $=0.640>0.05$, thus making it an insignificant relationship.

In measuring the assurance variable, the researchers focused to know the knowledge levels of all the frontline healthcare service delivery staff. This variable capitalizes on how the staff can instill confidence in the patients through effectively executing their tasks and rendering services without supervision. The knowledge of the job, is visible in the execution of tasks and this supposedly impacts the confidence a customer has in the services being delivered. Analyzed responses indicate that there is a significant response between the assurance, responsiveness and the empathy, $\mathrm{P}=0.10<0.05$ for responsiveness and $\mathrm{P}=0.30$ $<0.05$ for empathy. Thus, all three service quality variables directly complement and impact each other. According to analysis, the response time taken to meet patient needs is significantly related to the knowledge of the job, and the total amount of personal attention that is being provided to the customers. In addition to that, the empathy variable focuses on how effectively the frontline staff understands the patients' plight. The understanding nature of the frontline staff is used to analyze the follow up procedures of the healthcare provider and how committed their workers are towards helping patients achieve their purposes. Using the correlation function between the empathy and other variables, analyzed data indicated that there is a significant relationship between the empathy, tangibles, responsiveness 
and assurance with $\mathrm{P}=0.00<0.05$ for tangibles, $\mathrm{P}=0.00$ $<0.05$ for responsiveness and $P=0.30<0.05$ for assurance. This indicates that if for instance, there is an improvement in the physical appearance of the healthcare facility, according to the analyzed data, there would also be a significant improvement in other variables. However, according to available and analyzed data, there is no significant relationship between the overall satisfaction and how much personal attention is shown to the patient. $\mathrm{P}=$ $0.257>0.05$ Implying that the overall satisfaction of the customer experience is not based on the amount of personal attention that is being shown to the customer.

\section{Overall satisfaction}

This section was calculated using correlation, and a frequency test was conducted to provide detailed information on the overall level of satisfaction of the services offered. A correlation analysis between the overall satisfactions of all other variables was necessary in determining what factors can directly influence patient satisfaction after services have been received. However, according to analyzed data, there is no significant relationship between the service quality variables and the overall satisfaction of the customers.

Table 2: Overall Satisfaction

\begin{tabular}{|c|c|c|c|}
\hline Label & Description & Frequency & Population \\
\hline HS & Highly Satisfied & $4.0 \%$ & 6 \\
S & Satisfied & $10.7 \%$ & 16 \\
N & Neutral & $42.0 \%$ & 63 \\
D & Dissatisfied & $34.0 \%$ & 51 \\
HD & Highly Dissatisfied & $9.3 \%$ & 14 \\
\hline
\end{tabular}

In Table 3 below, it indicates a numerical analysis of the hypotheses generated for the purpose of this study. Using correlation and descriptive analysis, all the three selected hypotheses were tested and validated based on different statistical values. Hypotheses 1 and 3 were analyzed using the descriptive frequency analysis, to show the level of satisfaction patients had with the services they received, while hypothesis 2 was analyzed using Pearson correlation with the significance value of $5 \%, P=0.00<0.05$. The researchers used this method to check for significant relationships between variables relating to service quality.

\section{Managerial Implications}

Based on the structure of the questionnaire used and the responses gotten, it is evident that although patients may be pleased with certain factors when receiving services, generally for overall satisfaction to be achieved all factors ranging from the tangibles to empathy need to be satisfactory. $10.7 \%$ and $4 \%$ of the respondents were satisfied and highly satisfied with the services they received and this cumulatively is a very low percentage of satisfied customers in any organization. Patient satisfaction is evidently not dependable on any particular factor, as such, it is important for healthcare providers to ensure that quality is being displayed from the physical appearance of the environment, to the confidence instilled in customers by the organizational staff. The Nigerian healthcare providers, particularly the public health care sector needs to focus on improving its modes of delivering services to customers ranging from the quality of employees, to the standardized equipment, so as to attain comparable standards internationally and in the private sector; as well as, improve the population of patients who leave the hospital premises satisfied. Although this study focuses on the quality of services being offered in the healthcare sector, the process can also be applied in every organization ranging from banking sector to hospitality, and even in government. Quality service always plays an important role in all organizations, as it determines the return or departure of a customer after a service received. This study has indicated that overall customer satisfaction is not dependable on any single particular factor, but rather the whole experience of the service received determines the level of satisfaction. Thus, applying this process in other organizations which involves direct customer experience will provide an insight as to where an organization is faulty in its service provision and identify a means on improving those factors and what factors to improve on.

Table 3: Testing of Hypotheses

\begin{tabular}{|c|l|l|c|}
\hline S/no. & \multicolumn{1}{|c|}{ Hypotheses } & \multicolumn{1}{|c|}{ Statistical techniques used and values. } & Result \\
\hline H1 & $\begin{array}{l}\text { Patient satisfaction is based on the quality of services being } \\
\text { offered by the organization. }\end{array}$ & $\begin{array}{l}\text { Using Descriptive Frequency Analysis. } 44.7 \% \text { of } \\
\text { participants were dissatisfied with the services. }\end{array}$ & VALID \\
H2 & $\begin{array}{l}\text { Patient satisfaction is guaranteed based on the state of the } \\
\text { infrastructure, and the physical appearance of the } \\
\text { environment. }\end{array}$ & $\begin{array}{l}\text { Using Correlation. P value }=0.00<0.05 . \\
\text { Results gotten P }=0.988>0.05 .\end{array}$ \\
\hline H0 & $\begin{array}{l}\text { Patient satisfaction is not based on service quality, but } \\
\text { solving the problem at hand. }\end{array}$ & $\begin{array}{l}\text { Using Descriptive frequency analysis. } \\
42 \% \text { Neutral Perspective }\end{array}$ & INVALID \\
\hline
\end{tabular}




\section{Conclusion and Scope for further research}

In conclusion, it is evident that the quality of service that is being provided by the Nigerian Healthcare providers is below satisfactory level. This indicates that the healthcare provider needs to work on the methods through which they provide services to their patients. The Nigerian public healthcare system is perceived to be complacent when it comes to delivery of services and maintenance or availability of reliable infrastructure. This as a result reduces the dependability and confidence in individuals has in the public healthcare providers. This study has gone to indicate that, there is need for improvement in various factors affiliated with providing services in our healthcare system, while also indicating that patient satisfaction is attained based on the overall experience, rather than certain variables or factors, thus, for maximum patient satisfaction, healthcare providers need to ensure that the delivery process, and those who are delivering the services. The researcher recommend that, for improvement of standard of services provided in healthcare facilities, all hospitals should conduct anonymous post service analysis on their patients, which could be used to analyze their level of satisfaction, as well as, get an insight into how to improve their services, based on customer comments. This exploratory research has taken up by the researchers with certain limitations. Firstly, this study mainly concentrated only on out-patients with no input from any in patient. Secondly, the research was focused only on Adamawa state, Nigeria. However for further research, the researchers propose that a wider population of public healthcare providers and regions are analyzed to get a broader perspective on the quality of services being provided by healthcare providers, particularly the public sector. Also, the researchers suggest that for further research the opinions of all patients, both in patients and out patients, be considered so as to provide a wider range of opinions to analyze.

\section{Reference}

Asadi-Lari, M., Tamburini, M., \& Gray, D. (2004). Patients' needs, satisfaction, and health related quality of life: Towards a comprehensive model. Health and Quality of Life, 2, 32. http://doi.org/10.1186/1477-7525-2-32

Babakus, E., \& Mangold, W. (1992). Adapting the SERVQUAL scale to hospital services: An Empirical Investigation. Health Service Research, 26(6), 767-786.

Chingang, U. D., \& Lukong, P. B. (N.D.). Using servqual model to assess service quality and customer satisfaction: An empirical study of groceries in Umea. Retrieved February 12, 2018, from http://www.diva-portal.org/smash/get/diva2:327600/fulltext01

Choi, K.-S., Lee, H., Chankon, K., \& Sunhee, L. (2005).
The service quality dimensions and patient satisfaction relationships in South Korea: Comparisons across gender, age and type of service. Journal of Services Marketing, 19, 140-149.

Ejim, A. (2014, March). Building a solid healthcare system in Nigeria. The News, 24, 51.

Gronroos, C. (1984). A service quality model and its marketing implications. European Journal of Marketing, 18, 36-44.

Kalaja, R., Myshketa, R., \& Scalera, F. (2016). Service quality assessment in healthcare sector: The case of Durres Public Hospital. 12th International Strategic Management Conference. Antalya, Turkey: Elsevier Ltd.

Lam, S. S. K. (1997). SERVQUAL: A tool for measuring patients' opinions of hospital service quality in Hong Kong. Total Quality Management, 8(4), 145-52.

Mohebifar, R., Hasani, H., Barikani, A., \& Rafiei, S. (2016). Evaluating service quality from patients' perceptions: Application of importance-performance analysis method. Osong Public Health Res Perspect, 7(4), 233-238.

Okafor, C. (2017, April 19). A Reflection on healthcare service in Nigeria and the challenges of medical tourism. Retrieved from http://www.businessdayonline.com /reflection-healthcare-services-nigeria-challenges-medical-t ourism/

Osunwa (2006). Healthcare Policy and Plans. Enugu, Nigeria: Fountain Books.

Parasuraman, A., Zeithaml, V. A., \& Berry, L. L. (1988). SERVQUAL: A multi item scale for measuring consumer perceptions of the service quality. Journal of Retailing, 64, 12.

Parasuraman, A., Zeithaml, V. A., \& Berry, L. L. (1994). Alternative scales for measuring service quality: A comparative assessment based on psychometric and diagnostic criteria. Journal of Retailing, 70, 201-230.

Peprah, A., \& Atarah, B. (2014, February). Assessing patient's satisfaction using SERVQUAL model: A case of Sunyani regional hospital, Ghana. International Journal of Business and Social Research(JBSR), 4(2), 133-143.

Rezarta, K., Redi, M., \& Francesco, S. (2016). Service quality assessment in health care sector: The Case of Durres Public Hospital. 12th International Strategic Management Conference.

Schoenfelder, T., Klewer, J., \& Kugler, J.(2011, June 29). Determinants for patient satisfaction: $A$ study among 39 hospitals in an in-patient setting in Germany. Retrieved from https://academic.oup.com/intqhc/article/23/5/503/186 4644

Tam, J. L. (2007). Linking quality improvement with patient satisfaction: A study of a health service center. Marketing intelligence and planning, 732-745.

Tenner, A. R., \& De Toro, L. J. (1992). Total Quality Management: Three steps to continuous improvement. 
Boston, MA: Addison-Wesley.

Welcome, D. M. (2011, Oct-Dec). The Nigerian Health care system: Need for integrating adequate medical intelligence and surveillance systems. Retrieved from https://www.ncbi.nlm.nih.gov/pmc/articles/PMC3249694/

Westbrook, R. (1981). Sources of consumer satisfaction with retail outlets. Journal of Retailing, 57, 8-85.

Worlu, R., Kehinde, O. J., \& Borishade, T. T. (2016). Effective customer exprience management in healthcare sector of Nigeria. International journal of pharmaceutical and healthcare marketing, 1044), 449-466.

Yesilada, F., \& Direktor E. (2010). Health care service quality: A comparison of public and private hospitals. African journal of business management, 4(6), 962-971.

Zarei, A., Arab, M., Froushani, A., Rashidian, A., \& Tabatabaei, S. (2012). Service quality of private hospitals: The Iranian patients' perspective. Health Services Research, 12(1), 31. 